\title{
A arqueogenealogia como ferramenta de pesquisa no campo da Atenção Psicossocial
}

\author{
The archeogenealogy as research tool in the field of Psychosocial \\ Attention
}

http://dx.doi.org/10.5007/2178-4582.2014v48n2p186

\author{
Ana Clara Magalhães Cunha, Cristina Amélia Luzio \\ e Soraia Georgina Ferreira de Paiva Cruz
}

Universidade Estadual Paulista "Julio de Mesquita Filho", Assis/SP, Brasil

\begin{abstract}
O objetivo deste trabalho é apresentar a perspectiva arqueogenealógica, inspirada na proposta teórico-filosófica de Michel Foucault, como ferramenta de pesquisa em psicologia social, mais especificamente no campo da Atenção Psicossocial. Para tanto, efetivamos uma problematização teórico-conceitual acerca dos principais conceitos que sustentam essa perspectiva de trabalho, quais sejam: história, poder, saber e verdade. Também apresentamos as possíveis articulações com a Psicologia Social e as propostas da Atenção Psicossocial. Buscamos, com isso, fortalecer o trabalho epistemológico como uma importante ferramenta para a problematização das verdades absolutas, dos discursos hegemônicos, dos estigmas e preconceitos que compõem o imaginário social acerca do campo da saúde mental e do sofrimento psíquico.
\end{abstract}

Palavras-chave: Arqueogenealogia; Atenção Psicossocial; Psicologia Socia
The aim of this paper is present the archeogenealogy perspective, inspired on Michel Foucault's theoretical-philosophical proposal, as a research tool for social psychology, more specifically for the field of Psychosocial Attention. For that, we carry out a theoretical-conceptual problematization about the main concepts that sustain this research perspective, namely: history, power, knowledge and truth. We also present some possible articulations with the Psychosocial Attention proposals. Thus, we aimed, to strengthen the epistemological research with an important tool for the problematization of absolute truths, the hegemonic discourses, the stigma and bias that compose the social imaginary on the mental health field and of psychological suffering.

Keywords: Archeogenealogy; Psychosocial Attention; Social Psychology

\section{Introdução}

O modelo epistemológico de ciência que predomina na sociedade ocidental - vinculado ou não à comunidade científica -, sustenta-se em uma organização cunhada no século XIX, junto ao projeto de modernidade, que se engendrou como forma hegemônica na produção de novos regimes de conhecimento e verdade. Os acontecimentos históricos, políticos e sociais desse período colocavam a necessidade de uma prática científica que favorecesse os interesses do Estado e sua (re)organização, guiados principalmente pela e para a construção de um ideal conceitual de racionalidade e, consequentemente, do homem e sua existência. 
Tal modelo organizativo de ciência se aproxima do que Thomas Khun (1975) designa por ciência normal, que se atrela a uma ideia de história enquanto um desenvolvimento linear e progressivo de fatos em direção a um ponto de vista privilegiado no presente. Guia-se, assim, por um paradigma único, e exclusivo, que organiza tanto as condições para sua caracterização como ciência, como as bases para a investigação em si. São regras, conceitos, modelos de aplicação e padrões de trabalho capazes de oferecer respostas satisfatórias aos problemas de investigação durante um determinado momento, uma determinada época (KHUN, 1975).

Ao determinar um paradigma como modelo único de trabalho, de aplicação da ciência, o pesquisador/cientista atua margeado pelos resultados esperados. O lugar do intelectual, aqui, é cerceado por uma ideia de neutralidade em relação ao campo e aos objetos de pesquisa. Não há, assim, a necessidade de construção do campo de estudos; esse pesquisador restringe sua ação somente ao campo de questões que possam ser resolvidas pelo paradigma vigente, questões que se julgam competentes para resolver. Nesse modo de ação, toda e qualquer problemática que não seja redutível à formulação do paradigma de referência é afastada dessa comunidade científica - o que ocorre, principalmente, com as questões de ordem social que não podem ser enunciadas nos termos compatíveis com os instrumentos e conceitos proporcionados pelo paradigma adotado (Ibid.).

Ante a tal modelo de organização e investigação científica, autores como Thomas Khun (1975), Boaventura de Sousa Santos (2003) e Michel Foucault (2005; 2011a; 2013) - cada um em seu tempo, e a seu modo - realizam problematizações a fim de movimentar outros modos de se pensar a ciência e seus modos de organização e produção do conhecimento. Os três autores seguem um caminho que destaca a construção do campo de estudos, inerente a todo o processo de investigação, fundamental à prática científica. Fogem, pois, dos modelos predeterminados de ação do intelectual e sua pretensa neutralidade, e distanciamento, em relação ao campo de trabalho.

Vamos nos ater, aqui, às propostas de Michel Foucault em prol desse caminho de rupturas com o estatuto das verdades universais a partir de suas problematizações a respeito do estatuto político da ciência. O filósofo francês trabalha uma visão crítica da ciência que a localiza como construção e prática históricas, a partir de uma ideia de história como descontinuidade. Busca pelas questões que dizem respeito às relações do discurso científico com as estruturas políticas e econômicas da sociedade; suporte histórico e institucional da produção de saber (FOUCAULT, 1996; 2011b; 2013).

Nessa proposta, o papel do intelectual é cerceado por uma ética e uma política que caminham no sentido da construção de um outro regime de produção: 
fazer, em seu domínio de competência, com que as pessoas apreendam o que está acontecendo (FOUCAULT, 2011; VEYNE, 2011). Esse intelectual, contudo, não é soberano e não escapa aos sistemas de poder. Consciente de sua parte nisso, o papel do intelectual é "(...) antes o de lutar contra as formas de poder exatamente onde ele é, ao mesmo tempo, o objeto e o instrumento: na ordem do saber, da 'verdade', da 'consciência', do 'discurso'” (FOUCAULT, 2011, p. 71).

Essas propostas e problematizações - a respeito do discurso científico, do papel e dos lugares do pesquisador/intelectual, da relação da produção científica com a verdade -, estão fortemente presentes nas discussões a respeito da organização e da prática de investigação científica das ciências humanas, questionando os lugares da prática de pesquisa positivista cartesiana em áreas como, por exemplo, a História, a Sociologia, a Pedagogia e, em nosso caso, a Psicologia e o campo da Atenção Psicossocial.

Com o intuito de acompanharmos as propostas contra hegemônicas dos modos de conceber e realizar a prática científica entendemos que a escolha teórico-metodológica envolve, para além da definição de técnicas e itinerários de pesquisa, uma dimensão ético-política do campo de estudos e do pesquisador envolvido. Método, em nosso entendimento, se configura como o início de um caminho, não prescritivo, a ser construído durante todo o itinerário da pesquisa; "falar de metodologia é considerar todo o conjunto de procedimentos que funcionam como opções teóricas e éticas no encaminhamento do processo de construção do conhecimento" (ARAGÃO et. al., 2005, p. 21).

Nesse caminho, o intuito deste trabalho é apresentar a perspectiva arqueogenealógica de Foucault como uma importante ferramenta para a pesquisa em Psicologia Social, mais especificamente na área da Atenção Psicossocial, como possibilidade de enfrentamento aos discursos e práticas hegemônicos que, de alguma maneira, predominam nas ações em saúde mental.

\section{A proposta teórico-filosófica de Michel Foucault}

As aproximações e entrelaçamentos entre Foucault e a Psicologia são longínquos. Ainda que sua formação acadêmica inicial tenha sido a partir da, e para a, Filosofia, a Psicologia, e a Psiquiatria, atravessaram sua vida, no âmbito profissional e pessoal, de muitas maneiras. Após a licenciatura em Filosofia na Sorbonne em 1948, Foucault decide licenciar-se, também, em Psicologia. À licenciatura, concluída em 1949, o filósofo acrescenta um diploma de Psicologia Patológica do Institut de Psychologie de Paris - "pois a psicologia é o caminho que escolheu" (ERIBON, 1990, p. 56).

Percebemos, assim, um lugar de destaque da Psicologia para a empreitada do filósofo francês em torno das interrogações a respeito do sujeito e seus 
modos de subjetivação. Nesses entrelaçamentos entre Filosofia e Psicologia, o sujeito tem lugar imprescindível - ainda que comumente imperceptível - nos trabalhos de Foucault.

Essa preocupação de Foucault com a historicidade do sujeito possibilitou - e possibilita - colocar em xeque práticas históricas e hegemônicas de exclusão e categorização do sujeito e seus processos subjetivos. Os trabalhos sobre a loucura, a prisão, a prática médica e a sexualidade deram visibilidade a temas marcados pela exclusão social e pela obscuridade do discurso científico, proporcionando que interrogações se espalhassem em todos os níveis sociais.

Destarte, na proposta teórico-filosófica de Michel Foucault, o sujeito recebe lugar de destaque nos processos históricos da constituição das relações de saber e de poder. Em um trabalho fundado na crítica da história, tal proposta afirma-se enquanto possibilidade de novos olhares ao sujeito, às relações entre poder e saber e as estruturas políticas, econômicas, sociais, culturais, que envolvem os processos subjetivos.

Quem, ou o que, podemos chamar sujeito na perspectiva foucaultiana? O sujeito é destacado pelo filósofo como uma derivada, um efeito de práticas discursivas e não discursivas construídas e consolidadas historicamente. O sujeito é constituído, e não constituinte, por atravessamentos discursivos, epistêmicos, políticos e culturais. As maneiras de realizar a experiência de si, os processos de subjetivação, são organizadas, então, conforme a produção e articulação de tais domínios historicamente; derivam do saber e do poder, mas não dependem deles (FOUCAULT, 2010) (ARAÚJO, 2001) (DELEUZE, 2005). Envolvem, pois, uma relação com o tempo e, com isso, o abandono de uma ideia de subjetividade marcada por imutabilidade e fixidez (CARDOSO JR., 2005).

Para localizar os modos de subjetivação em seus atravessamentos, históricos e mutantes, Foucault organiza seus trabalhos em torno de três eixos problematizadores: os modos de investigação, as práticas divisoras e o modo pelo qual o sujeito realiza a produção de si. Esses eixos organizam-se em perspectivas de análise complementares e interdependentes, comumente conhecidas como: arqueologia do saber; genealogia do poder e estética da existência. Ainda que apresentadas por Foucault, com seus distanciamentos e aproximações, o filósofo jamais objetivou a criação de uma metodologia categórica, com regras precisas e encerradas em si.

Desse impasse, emergem algumas interrogações que conduzem nosso trabalho: é possível falar de método em Foucault? Se consideramos a metodologia na perspectiva de um percurso, para o pesquisador/intelectual, de produção de si e do caminho da pesquisa, tal como apresentamos anteriormente, sim. 
Nesse sentido, numa tentativa de situar a obra do filósofo francês sem categorizá-la duramente, nos aproximamos de Deleuze (2005) quando propõe pensar o trabalho de Foucault direcionado por três interrogações (concernentes à leitura de Foucault a Kant) que se compõem, quais sejam: $O$ que posso saber?; O que devo fazer?; Quem somos nós? Outra ressonância é a proposta do filósofo catalão Miguel Morey, que propõe trabalhar o pensamento de Foucault direcionado pelo atravessamento da ontologia histórica, guiada pela interrogação: Quem somos nós nesse momento preciso da história? O filósofo apresenta,assim, a ontologia de nós mesmos: a) em relação às verdades que nos constituem como sujeitos do conhecimento - o saber; b) nas relações de poder que nos constituem como sujeitos atuando uns sobre os outros - o poder; e c) em relação à ética por meio da qual nos tornamos sujeitos - a ética (MOREY, 1991).

No Brasil, encontramos, ainda, Alfredo Veiga-Neto (2007) que se inspira nessa proposta e propõe pensar os domínios foucaultianos que se compõem e complementam e, assim como sugere Morey (1991), localizam o sujeito (o domínio do ser) como o elemento fundamental. Tais domínios são nominados: ser-saber, ser-poder e ser-consigo. Como domínios, ou como ontologias, não há, pois, uma divisão categórica da obra, uma vez que, um mesmo trabalho, como por exemplo, A história da loucura na idade clássica (1961) - um trabalho comumente considerado de cunho estritamente arqueológico - pode ser localizado em diferentes domínios e no domínio principal: a problematização do sujeito e os modos de subjetivação.

Tal como destaca Morey:

Como é de todo evidente, pelo menos a posição que ocupa $A$ História da Loucura nos três eixos, nos convida a desconfiar, seriamente, tanto da periodização tradicional como da hipótese de uma sucessão de métodos ao longo de seu itinerário intelectual, mostrando-nos, ao contrário, as diferentes aberturas de uma mesma tarefa geral (1991, p. 25, grifos do autor, tradução livre).

As propostas, de Deleuze (2005), Morey (1991) e Veiga-Neto (2007) possibilitam perceber os domínios, os momentos do trabalho de Foucault, como uma sucessão de incorporações que corroboram para uma expansão do campo de problematizações e do modo de trabalhá-las. Favorecem, e vão ao encontro, da proposta do filósofo, desenvolvida em companhia de Deleuze, e apresentada na conversa $O$ s intelectuais e o poder (2011a), de localizar a teoria como caixa de ferramentas, completamente atrelada ao posicionamento político do pesquisador e do caminho construído ao longo do campo de trabalho. 
Ao considerarmos que aquilo que Foucault nos oferece é, então, uma caixa de ferramentas, podemos pensar as melhores maneiras de utilizar sua proposta teórico-filosófica em nosso campo de trabalho. É com base nas proposições dos três pensadores anteriormente apresentados que localizamos nossa apreensão do trabalho de Foucault e as possibilidades de sua utilização como ferramenta para a pesquisa. Apreendemos, assim, os "três Foucault" como um só, considerando que seu trabalho se organiza em torno de um liame e que, de acordo com o campo em que emerge e se insere, dá destaque a diferentes problemáticas e a elementos específicos que compõem os processos de subjetivação: ora o saber, ora o poder, ora a subjetividade. Todos, contudo, completamente imbricados.

Ante a isso, optamos por trabalhar especificamente a partir da perspectiva da arqueogenealogia como ferramenta de pesquisa no campo da Atenção Psicossocial. Cabe aqui destacar que não apresentamos a arqueogenealogia como um conceito - mesmo porque isso seria um paradoxo ante à problematização a respeito da sistematização do trabalho de Foucault -, mas sim como uma perspectiva de trabalho que nos permite articular as produções, formações e práticas discursivas e não discursivas que envolvem o campo de trabalho. Apresentamos, assim, a arqueogenealogia como uma articulação teórico-metodológica, em interlocução com alguns estudiosos do pensamento de Foucault que auxiliam nossa discussão e a construção de nossa apreensão (ARAÚJO, 2001; 2007; PAIVA, 2000; ZAMBENEDETTI; SILVA, 2011; LEMOS; CARDOSO JR, 2009).

\section{Arqueogenealogia: problematizando história, poder, saber e verdades}

Para empreendermos nossa leitura a respeito da perspectiva arqueogenealógica é importante elucidar algumas noções que consideramos articuladoras do pensamento de Foucault e que compõem a arqueogenealogia como ferramenta de pesquisa; quais sejam: as noções de história, verdade, poder e saber. Tais noções, como problematizamos, não devem ser tratadas isoladamente, tampouco podemos destacar uma em detrimento da outra. Cruzam-se e compõem-se a todo momento.

O trabalho crítico da/com a história, vista como descontinuidade, é o propulsor da perspectiva arqueogenealógica. A descontinuidade como instrumento e campo de pesquisa, figura, assim como um dos elementos fundamentais à análise histórica. Solidifica-se, desse modo, a perspectiva do diagnóstico crítico do presente, na qual os acontecimentos históricos não são percebidos enquanto um encadeamento linear de fatos aos quais a história acresce sentidos e essências; mas, sim, como uma relação de forças no jogo da história, campo de descontinuidade e multiplicidades (FOUCAULT, 2011c). 
Propõe, com isso, uma mudança em nossos olhares, usos e relações com o passado e a história. Suspender as unidades preestabelecidas pela história tradicional - contínua -, as universalidades, as totalizações, e questioná-las em todos os níveis de sua construção; dissipar as raízes e trazer à tona todos os acontecimentos que nos atravessam.

Temos, assim, organizada, uma escuta cuidadosa à história que modifica consigo a noção de verdade, desconstruindo as relações imediatas entre saber científico e discurso verdadeiro. Foucault localiza a verdade - e sua produção - como questão política, amplamente atrelada ao poder, às relações de poder, e que, consequentemente, recai sobre os processos de produção de saberes e unidades discursivas. Falamos, então, de verdades produzidas e legitimadas em determinado campo discursivo; "cada sociedade tem seu regime de verdade, sua "política geral" de verdade [...]" (FOUCAULT, 2011c, p. 12).

Nesse viés, as noções de saber e poder também são inscritas na história e, portanto, em processos de desnaturalização e desconstrução. Disso sucede uma problematização específica que investe em uma extensão da definição do poder para além da dimensão jurídico-legal e estatal (FOUCAULT, 1991; 2010). Uma investigação crítica da temática do poder que não o considera como algo concreto - representado pelo Estado, por exemplo -, nem tampouco, exclusivamente, como estrutura de dominação mas, sim, como ação, como ato: ação sobre a ação do outro, composta por uma diversidade de encaminhamentos (FOUCAULT, 2010).

O poder como ação coloca também em jogo as relações entre os indivíduos, seus conjuntos de ações. Por isso, proceder com a análise do poder junto à análise da história e dos regimes de verdade é percurso indispensável ao nos aproximarmos dessa filosofia crítica do sujeito.

Outro traço fundamental à noção de poder como prática social é a interdependência entre poder e saber. Não há relações de poder sem a constituição de um campo de saber, e, da mesma forma, todo saber constituirá novas relações de poder. Opera-se, assim, uma desconstrução, também, da vinculação imediata entre ciência e saber. Saber, aqui, já não é considerado subproduto de uma ciência constituída. Ao contrário, é pensado como um conjunto de elementos, formados de maneira regular por uma prática discursiva, e indispensável à constituição de uma ciência, sem, contudo, se destinar necessariamente a dar lugar a um discurso científico (FOUCAULT, 2013).

Aqui, percebemos em evidência o trabalho com a desnaturalização das verdades, que se inicia já com a operação dos deslocamentos conceituais nas noções de saber e poder. Para articulação desse processo, é imprescindível elucidar: a) as relações, e os jogos, existentes entre poder e saber; b) os modos 
pelos quais, ao se entrelaçarem, articulam condições e possibilidades para a emergência de determinado campo discursivo, em uma determinada época; c) os processos pelos quais as produções discursivas se consolidam enquanto enunciados verdadeiros e universais. É sobre esse campo que a arqueogenealogia se debruça.

\section{A descrição arqueogenealógica e a problematização das práticas discursi- vas e não discursivas}

Compreendemos a arqueogenealogia exatamente a partir da articulação do binômio saber-poder. Se problematizamos as relações de saber e poder como interdependentes e complementares, uma sendo possível somente em relação à outra, a arqueogenealogia pode ser considerada como possibilidade para a problematização constante entre discurso, verdade, poder e saber, elucidando historicamente a emergência dos objetos e enunciados. Podemos considerar A História da loucura na idade clássica (2010b), tese de doutorado de Foucault, publicada originalmente em 1961, como uma primeira ilustração desse trabalho crítico com a história e os saberes. Nela, o filósofo elabora uma história da desrazão, descontínua; e, inserindo a loucura em um regime de historicidade específico, problematiza os percursos pelos quais ela emerge enquanto objeto e conceito no campo discursivo médico-psiquiátrico da ciência moderna (FOUCAULT, 2010).

A pesquisa arqueogenealógica rompe com a noção de história contínua e linear, permitindo-nos operar com a multiplicidade de acontecimentos dispersos na problematização das práticas de poder, de subjetivação e discursivas; a relação entre as formações de um discurso e certo conjunto de acontecimentos. Como organizamos, então, um trabalho arqueogenealógico? A título de elucidação, explanaremos a arqueologia e a genealogia separadamente para que possamos destacar as especificidades de cada uma, bem como identificar os elementos de articulação entre elas.

A arqueologia é descrita por Foucault, em suas especificidades, na Arqueologia do saber (2013), como uma experiência crítica das configurações do saber, daquilo que tornou possível que algo fosse dito em determinado campo do saber; bem como as ideias e teorias que surgem desse espaço. Nas palavras do filósofo,

(...) esse termo [arqueologia] não incita à busca de nenhum começo; não associa a análise de nenhuma exploração ou sondagem geológica. Ele designa o termo geral de uma descrição que interroga o já dito no nível de sua existência; da função enunciativa que nele exerce, da formação discursiva a que pertence, do sistema geral de arquivo de que faz parte (FOUCAULT, 2013, p.161). 
No caminhar em direção à produção dessa outra história, o documento - e o trabalho documental -, também aparecem como elementos importantes de problematização. $\mathrm{O}$ documento passa a ter um lugar diferente: já não é mais matéria inerte, cuja interpretação possibilitaria uma reconstrução do "verdadeiro passado", de uma memória coletiva, explicação de grandes períodos históricos - monumentos transformados em documentos; trata-se, agora, do contrário, "monumentalizar os documentos", trabalhá-lo em seu interior estabelecendo séries, unidades e relações, multiplicando as rupturas (FOUCAULT, 2013). Resumindo,

\begin{abstract}
[...] a história, em sua forma tradicional se dispunha a 'memorizar' o monumentos do passado, transformá-los em documentos e fazer falarem esses rastros que, por si mesmos, raramente são verbais, ou que dizem em silêncio coisa diversa do que dizem: em nossos dias, a história é o que transforma os documentos em monumentos e que desdobra, onde se decifravam rastros deixados pelos homens, onde se tentava reconhecer em profundidade o que tinha sido uma massa de elementos que devem ser isolados, agrupados, tornados pertinentes, inter-relacionados, organizados em conjuntos (FOUCAULT, 2013, p.8, grifos do autor).
\end{abstract}

O arqueólogo se ocupa, assim, da descrição e análise das discursividades para encontrar a partir de que conhecimentos e teorias os campos de saber se tornaram possíveis, em que espaço de ordem se constituíram. Uma maneira de interrogar os fatos em um nível mais profundo, e renunciar à função de garantir uma infinita continuidade ao discurso, de remetê-lo a uma longínqua origem - presença da origem -, para tratá-lo, agora, no próprio jogo de sua instância (FOUCAULT, 1996; 2013). O domínio do discurso é, então, constituído por um campo de acontecimentos discursivos.

Disso decorre o que Foucault nomeou projeto de descrição dos acontecimentos discursivos em oposição à análise linguística dos discursos. O trabalho descritivo se constituiu, assim, como possibilidade para estabelecer outras relações, que não as já determinadas e condicionadas, entre os fatos e os acontecimentos enunciativos. Tratar o discurso não mais somente como um conjunto de signos, como um estado final da produção de saber; mas sim enquanto prática discursiva - que forma os objetos de que fala.

[...] gostaria de mostrar que os "discursos", tais como podemos ouvi-los, tais como podemos lê-los sob a forma de texto, não são, como se poderia esperar, um puro e simples entrecruzamento de coisas e palavras [...] Certamente os discursos são feitos de signos; mas o que fazem é mais que utilizar esses signos para designar coisas. É esse mais que os torna irredutíveis 
à língua e ao ato da fala. É esse "mais" que é preciso fazer aparecer e que é preciso descrever (FOUCAULT, 2013, p. 59/60, grifo do autor).

Esse trabalho com os objetos, e seus regimes de produção, indica exatamente o trabalho histórico que não se ocupa da busca por um solo originário de criação, mas sim de uma história que relacione o conjunto de regras que permitem formulá-lo. Ao descrever a formação dos objetos de um discurso se identificam, simultaneamente, as relações que caracterizam determinada prática discursiva. As práticas discursivas são localizadas, então, como lugar onde se forma ou se desmancha, onde aparece e se apaga uma pluralidade de objetos (Ibid.).

A descrição arqueológica pode ser caracterizada, então, como uma atividade de reescrita da história no plural, sem pretensão de tornar-se universal. Percorre o eixo prática discursiva $\rightarrow$ saber $\rightarrow$ ciência, considerando o campo discursivo científico exatamente em sua existência histórica.

Debruçar-se sobre a história, e a existência histórica dos saberes possibilita, assim, o aparecimento das relações entre os domínios discursivos e não discursivos no campo da produção dos objetos de saber. Tentar determinar como as regras de formação, das quais o discurso depende, podem estar articuladas aos sistemas não discursivos e quais as especificidades dessas formas de articulação. É sobre esse "algo a mais" das produções discursivas que a genealogia se debruça.

Se a arqueologia interroga "Como?" foi possível a emergência de um enunciado, de um campo de produção de saberes; a genealogia interroga "Por que?" uma prática discursiva foi possível em determinado momento histórico.

A genealogia exige, portanto, uma minúcia dos saberes para que possa, então, desdobrar-se no trabalho com os acontecimentos e elementos que configuram práticas não discursivas, bem como a introdução da questão do poder como instrumento para uma análise capaz de explicar a relação dos saberes (MACHADO, 2011). Investe, tal como a descrição arqueológica, no trabalho com uma história avessa às origens e às afirmações de essências e universalidades. Uma história das transformações.

Ora, se o genealogista tem o cuidado de escutar a história em vez de acreditar na metafísica, o que é que ele aprende? Que atrás das coisas há "algo inteiramente diferente": não seu segredo essencial e sem data, mas o segredo que elas são sem essência, ou que sua essência foi construída peça por peça a partir de figuras que the eram estranhas. [...] O que se encontra no começo histórico das coisas não é a identidade ainda pre- 
servada da origem - é a discórdia entre as coisas, é o disparate (FOUCAULT, 2011c, p. 17-18).

\begin{abstract}
A atividade genealógica reforça, assim, a operação dos cortes das relações deterministas empregadas entre as palavras e as coisas. Opera com a busca por descontinuidades, com o deslocamento do lugar de imutabilidade das verdades e suas relações com o poder; “(...) é exatamente contra os efeitos de poder próprios de um discurso considerado científico que a genealogia deve travar o combate" (FOUCAULT, 1999, p.14). Um deslocamento do plano das formas para o plano das forças.
\end{abstract}

A inserção do trabalho genealógico no plano das forças permite que nos debrucemos sobre os efeitos produzidos pelos dispositivos - discursivos ou não - sobre os corpos e as populações. Efeitos esses que podemos considerar como as linhas para a problematização dos modos pelos quais, historicamente, nos tornamos sujeitos na articulação entre saber e poder. Mais que conhecer o passado, a genealogia nos permite, então, conhecer o presente, operar uma história do presente.

Preservadas suas especificidades, e destacadas suas complementaridades, não há dificuldade em processar a articulação das duas perspectivas de traba1ho. Nas palavras do próprio Foucault "a arqueologia seria o método próprio das análises das discursividades locais e a genealogia seria a tática que, a partir das discursividades locais assim descritas, colocam os saberes em jogo, liberados da sujeição que surgem delas" (FOUCAULT, 1993, p. 17).

Ainda que não possamos definir um itinerário técnico para o trabalho com a arqueologia e a genealogia, pois estaríamos em contradição com a proposta teórico-filosófica, há um compromisso ético e político que permeia e orienta essa perspectiva de trabalho. Tal compromisso se constitui, justamente, por um olhar e escuta cuidadosos à história e aos acontecimentos que consolidem práticas - discursivas e não discursivas - que busquem se distanciar das filosofias transcendentais e das produções de novos regimes de verdades. Retomando, ainda, a proposta de uma teoria como caixa de ferramentas, permite-se que cada pesquisador a desenvolva à sua maneira; contudo, sem perder de vista a dimensão política, e de produção de si, que envolvem o trabalho (do) intelectual.

Consideramos, assim, a arqueogenealogia como perspectiva de trabalho para nossa pesquisa pois nos possibilita: problematizar as práticas discursivas, e não discursivas, que envolvem os saberes engendrados no campo da saúde mental e, assim, alcançar e compor com as propostas e ações de ruptura orga- 
nizadas pelo movimento da Reforma Psiquiátrica Brasileira e pelas estratégias da Atenção Psicossocial.

\section{Arqueogenealogia e Atenção Psicossocial: rupturas epistemológicas ao alcance das práticas e concepções sociais}

As aproximações entre a proposta filosófica de Foucault, a Psicologia e os movimentos de Reforma Psiquiátrica são longínquas. A História da loucura na idade clássica $(2010 \mathrm{~b})^{1}$ torna-se referência fundamental - como base e força - para movimentos de contestação às práticas vigentes até a segunda metade do século XX. A investida do filósofo em uma crítica à história tradicional abarca, nesse livro, a problematização do discurso, e do saber, médico e psiquiátrico e suas práticas em relação à - produção da - loucura. Esse trabalho crítico com as discursividades ultrapassa a dimensão linguística, e nos possibilita acompanhar e desnaturalizar o processo histórico, composto por um conjunto de elementos que articulam e localizam a experiência da loucura sob o crivo do saber psiquiátrico.

A crítica centrada nas tecnologias de enclausuramento e na tutela - discursiva e não discursiva - da medicina sobre a loucura constitui-se, assim, como cerne dessa aproximação, uma vez que as investidas dos movimentos anti-psiquiátricos se organizaram exatamente em torno de possibilidades de ruptura com a relação ao poder-saber que consolidou o discurso psiquiátrico e sua produção conceitual sobre a loucura.

Os movimentos em prol das reformas psiquiátricas emergiram em diferentes partes do mundo durante a segunda metade do século XX. Alguns dos mais expressivos, e considerados como bases para os movimentos sucessores, foram: a Comunidade Terapêutica na Inglaterra; a Psicoterapia Institucional na França; a Psiquiatria de Setor, também na França; a Psiquiatria Preventiva, nos Estados Unidos da América; a Anti-Psiquiatria na Inglaterra; e a Psiquiatria Democrática na Itália. Ainda que com especificidades e diferenças em suas propostas de cuidado, estavam próximos pelo compromisso em comum de romper com o paradigma de tratamento psiquiátrico vigente à época (AMARANTE, 2007; LUZIO, 2010).

Todas essas experiências corroboraram para a organização do Movimento da Reforma Psiquiátrica Brasileira. Destacamos, entre elas, a Psiquiatria Democrática Italiana que se caracteriza pelos questionamentos não só em relação

\footnotetext{
${ }^{1}$ Destacamos A História da loucura da idade clássica como o principal ponto de aproximação entre os movimentos de reforma psiquiátrica e o filósofo francês. Contudo, cabe destacar que não só esse trabalho adquiriu importância. O conjunto da obra de Foucault merece destaque, uma vez que o autor não cessou de problematizar, à luz de diferentes temáticas, a necessidade de revisitarmos os processos históricos de constituição dos sujeitos na sociedade ocidental.
} 
às condições de cuidado, mas também ao modelo científico da psiquiatria e dos conceitos elaborados por ela. Tal processo de reforma considera, pois, que "a transformação deva transcender à simples reorganização do modelo assistencial e alcançar as práticas e concepções sociais" (ROTELLI apud AMARANTE, 2007, p. 59).

O movimento da Reforma Psiquiátrica brasileira também se organiza no sentido de ultrapassar as reformas institucionais e de organização dos serviços, e centra-se na problematização do campo da Saúde Mental e da Atenção Psicossocial enquanto um Processo Social Complexo atravessado, historicamente, por um entrelaçamento de elementos (AMARANTE, 2007).

Dentro desse processo, Paulo Amarante (2007) propõe pensarmos a Atenção Psicossocial a partir de dimensões, a fim de abarcar todos os elementos que atravessam os sujeitos em sofrimento psíquico e seus processos de subjetivação. As dimensões são organizadas em quatro eixos: jurídico-político; sócio-cultural; técnico-assistencial e teórico-conceitual (ou epistemológico). A dimensão jurídico-política é composta por todo um arcabouço legal ${ }^{2}$ que garanta o exercício da cidadania dos sujeitos em sofrimento psíquico. A dimensão sócio-cultural se organiza, também, como estratégia fundamental para a efetivação do envolvimento da sociedade na discussão do movimento da reforma psiquiátrica. Abre possibilidade para a desconstrução dos imaginários sociais a respeito da loucura, do sofrimento, dos tratamentos, bem como enquanto incentivo para a participação social junto às políticas de saúde de maneira geral.

A dimensão técnico-assistencial envolve a reorganização dos serviços, das políticas de cuidado e tratamento, o investimento na formação dos profissionais. Opera como um recurso imprescindível para a articulação das transformações políticas e sociais, com uma interface importante junto à dimensão teórico-conceitual.

Por fim, a dimensão teórico-conceitual, ou epistemológica, é caracterizada como "o conjunto de questões que se situam no campo teórico-conceitual e que dizem respeito à produção de conhecimentos que fundamentam e autorizam o saber/fazer médico-psiquiátrico" (AMARANTE, 2007, p. 1). Desse modo, a problematização das relações entre ciência e poder tornam-se fundamentais para o trabalho com a revisão de conceitos e da ideia de produção de

\footnotetext{
${ }^{2}$ A organização desse arcabouço legal foi consolidada a partir da década de 1990. Nesse período foram promulgadas Leis, Portaria e Decretos em nível nacional, estadual e federal, colaborando para o avanço da Atenção Psicossocial como estratégia de cuidado aos sujeitos em sofrimento psíquico. Um dos textos que adquiriu destaque foi a Lei 10.216 de 6 de abril de 2001 que dispõe sobre "a proteção e os direitos das pessoas portadoras de transtornos mentais e redireciona o modelo assistencial em saúde mental". Tal texto tem como base a proposta original apresentado pelo Deputado Paulo Delgado em 1989, que tramitou no Congresso durante 12 anos e teve sua versão final aprovada, com modificações, no ano de 2001.
} 
verdades universais que perpetuarem a loucura sob as noções de periculosidade, alienação, anormalidade, exclusão. É junto a essa dimensão que aproximamos arqueogenealogia e da Atenção Psicossocial.

O trabalho epistemológico se faz, ainda, mais importante quando encontramos nos relatórios das Conferências Nacionais de Saúde Mental destaque para esse processo de questionamento e interrogações aos saberes hegemônicos vigentes. Como encontramos no texto do relatório da primeira Conferência que indica a necessidade de "revisão dos pressupostos das práticas preventivas e educativas em saúde mental, no sentido de se impedir a disseminação de práticas de controle social pela impregnação ideológica do saber" (MINISTÉRIO DA SAÚDE, 1988, p. 19). E no texto da segunda Conferência, em uma oficina a respeito da reforma psiquiátrica e as tecnologias de cuidado, onde se problematiza a tutela do campo psi sobre a loucura:

Com o passar do tempo assiste-se à lenta mas segura instauração de um vasto campo de saberes e práticas [...] cujo núcleo inicial se constitui em torno do saber e da sua capacidade de legislar sobre a normalidade, expandindo-se em círculos concêntricos cada vez mais amplos. Esses saberes acabam por constituir algo que poderia se designar como campo "psi". Investigar a formação desse campo - suas continuidades e rupturas internas, bem como o modo como o mesmo se articula com os saberes e práticas populares - é fundamental também para a compreensão das questões e dos impasses que ocorrem no âmbito da prática assistencial em saúde mental (MINISTÉRIO DA SAÚDE, 1988, 1992, p. 35-36).

\section{Considerações finais}

Podemos localizar a discussão sobre as ciências, as práticas científicas e suas relações com as práticas e concepções sociais, no bojo mais profundo do movimento da Reforma Psiquiátrica. As rupturas epistemológicas, propostas tanto por Foucault como pela Atenção Psicossocial, se articulam à medida que se comprometem com a transformação da própria ciência; com o rompimento com o saber naturalizado da psiquiatria.

Em suma, esta dimensão nos transporta à reflexão dos conceitos mais fundamentais da psiquiatria que [...] foi fundada em um contexto epistemológico em que a realidade era considerada um dado natural, capaz de ser apreendida e revela em sua plenitude. Nasceu em um contexto em que a ciência significava a produção de um saber positivo, neutro e autônomo: expressão unívoca da verdade! Assim é que os conceitos psiquiátricos devem ser avaliados [...] (AMARANTE, 2007, p. 66). 
A arqueogenealogia permite que nos debruçemos, exatamente, sobre a investigação desse processo histórico de organização da psiquiatria e do discurso psiquiátrico, e seus efeitos sobre os processos de constituição dos sujeitos.

$\mathrm{O}$ compromisso ético-político, imprescindível às duas propostas, possibilita, assim, não só deslocar as naturalizações conceituais sustentadas por discursos médico-psiquiátricos específicos, mas, principalmente, deslocar a concepção de sujeito fundada sob ideais de normalidade; pensar o sujeito como efeitos de práticas discursivas e não discursivas e que deve ser considerado sempre em termos dessa multiplicidade; e, ainda, problematizar o lugar de cada um - enquanto pesquisador, profissional da saúde, sociedade civil -, nesse processo social complexo.

Nesse contexto, consideramos a problematização teórico-conceitual, e o trabalho com o aparato documental, como um importante instrumento de problematização das verdades absolutas, dos discursos hegemônicos, dos estigmas e preconceitos que compõem o imaginário social. E, com isso, construir e fortalecer possibilidades de rupturas que alcancem as práticas e concepções sociais a respeito dos processos de subjetivação, do sofrimento psíquico, das políticas públicas de saúde mental, das estratégias de cuidado.

A perspectiva arqueogenealógica, enquanto dimensão epistemológica da Atenção Psicossocial se constitui, pois, como um processo importante ao optarmos por trabalhar com a análise das produções e formações discursivas e não discursivas que envolvem o campo da saúde mental.

Como destaca Vera Portocarrero (2009), essa proposta filosófica crítica, ética e política, se faz importante na medida em que

[...] exige um esforço permanente do pensamento para esca-
par de si mesmo e a tentativa de mostrar que as pessoas são
muito mais livres do que pensam [...]; torna visíveis as falsas
necessidades tanto das práticas quanto de temas considerados
evidentes e verdadeiros e que foram fabricados, permitindo, as-
sim, criticar e destruir sua pretensa evidência. Do ponto de vista
político, esse quadro mostra-se relevante, na medida em que
possibilita responder à questão quem somos nós no presente
e como nos tornamos quem somos, de modo a provocar novas
formas de pensar sobre nós mesmos e sobre o mundo (PORTO-
CARRERO, 2009, p. 144).

Debruçarmo-nos, então, sobre os discursos da psiquiatria, da psicologia, da atenção psicossocial se constitui como possibilidade para compreender as implicações históricas das relações entre saber, poder, discursos e práticas sociais nos processos de medicalização e psiquiatrização social. Bem como, para a consolidação de mudanças nas mentalidades, nas concepções, práticas 
e relações sociais favorecendo o fortalecimento das estratégias e dispositivos da Atenção Psicossocial compromissados com a afirmação da saúde mental como um processo social complexo.

\section{Referências}

AMARAnTE, Paulo. Saúde Mental e Atenção Psicossocial. Rio de Janeiro: Editora Fiocruz, 2007. 119 p.

ARAGÃO, Elisabeth Maria et. al. Falando de metodologia de pesquisa. In: Estudos e pesquisa em Psicologia. Rio de Janeiro: 2005, p. 18-28.

ARAÚJO, Inês Lacerda. Foucault e a crítica do sujeito. Curitiba: Ed. Da UFPR, 2001.

. Formação discursiva como conceito chave para a arqueogenealogia de Foucault. In:

$\overline{\mathrm{RAGO}}, \mathrm{M}$; MARTINS, A. L. Dossiê Foucault. Revista Aulas, [S.1.], n.3, p. 1-24, 2007.

CARDOSO JR., Hélio Rebello. Para que serve uma subjetividade? Foucault, tempo e corpo. Psicologia: reflexão e crítica [S.1.], v.18, n. 3, p. 343-349, 2005.

DELEUZE, Gilles. Foucault. Trad: Cláudia Sant'Anna Martins. $6^{\mathrm{a}}$ reimpressão da $1^{\mathrm{a}}$ ed. São Paulo: Brasiliense, 2005.

ERIBON, Didier. Foucault (1926-1984). Trad: Hildegard Feist. São Paulo: Companhia das Letras, 1990.

FOUCAULT, Michel. Genealogía I: erudición y saberes sujetos. In: Genealogía del racismo. Buenos Aires: Altamira, 1993, p. 11-22.

. A ordem do discurso. Aula inaugural no Collège de France. Trad: Laura Fraga de Almeida Sampaio. São Paulo: Edições Loyola, 1996.

Em defesa da sociedade. Trad: Maria de FátimaErmantinaGalvão. São Paulo: Martins Fontes, 1999. 382 p.

Arqueologia das ciências e história dos sistemas de pensamento. Coleção Ditos e

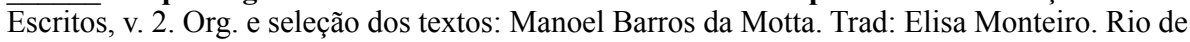
Janeiro: Forense Universitária, 2005. 376 p.

O sujeito e o poder. In: DREYFUS, H. L.; RABINOW, P. Michel Foucault - uma trajetória filosófica: para além do estruturalismo e da hermenêutica. Trad: Vera Portocarrero e Gilda Gomes Carneiro. Rio de Janeiro: Forense Universitária, 2010, p. 273-295.

.História de loucura na Idade Clássica. Trad. José Teixeira Coelho Neto. $9^{\mathrm{a}}$ ed. São Paulo: Perspectiva, 2010b, 351p. 2011, $295 \mathrm{p}$.

Microfísica do poder. Org. e trad.: Roberto Machado. Rio de Janeiro: Edições Graal, . Os intelectuais e o poder. In: FOUCAULT, M .Microfísica do poder. Rio de Janeiro: 
CUNHA, A. C. M.; LUZIO, C. A.; PAIVA CRUZ, S. G. F. A arqueogenealogia como ferramenta de...

Edições Graal, 2011a, p. 69-78.

Verdade e poder. In: FOUCAULT, M. Microfísica do poder. Rio de Janeiro: Edições Graal, 2011b, p. 1-14.

Nietzsche, a genealogia e a história. In: FOUCAULT, M. Microfísica do poder. Rio de Janeiro: Edições Graal, 2011c, p. 15-37.

A Arqueologia do Saber. Trad: Luiz Felipe Baeta Neves. Rio de Janeiro: Forense Universitária, 2013. 254 p.

KHUN, Thomas. A estrutura das revoluções científicas. Trad: Beatriz Vianna Boeira e Nelson Boeira. São Paulo: Perspectiva, 1975, 262 p.

LEMOS, Flávia Cristina Silveira; CARDOSO JR., Hélio Rebello. A Genealogia em Foucault: uma trajetória. Psicologia \& Sociedade, Florianópolis, v.21, n.3, p. 353 - 357, 2009.

LUZIO, Cristina Amélia. Atenção Psicossocial: reflexões sobre o cuidado em saúde mental no Brasil. Tese [Livre-Docência] Assis, SP. 2010. (não publicada, cedida pelo autor).

MACHADO, Roberto. Por uma genealogia do poder. In: FOUCAULT, M. Microfísica do poder. Rio de Janeiro: Edições Graal, 2011b, p. VII - XXIII.

MINISTÉRIO DA SAÚDE (Secretaria Nacional de Programas Especiais de Saúde). Conferência Nacional de Saúde/8. I Conferência Nacional de Saúde Mental: relatório final/8, Brasília, 25 a 28 de junho de 1987, Centro de documentação do Ministério da Saúde: Brasília, 1988.

(Coordenação de Saúde Mental). 2a . Conferência Nacional de Saúde Mental. A Reestruturação da Atenção em Saúde Mental no Brasil. Brasília, 1 a 4 de dezembro de 1992, Brasília, DF: Ministério da Saúde, 1992.

MOREY, Miguel. La cuestión del método. In: FOUCAULT, M. Tecnologías del yo y otros textos afines. Barcelona: Paidós Ibérica, 1991, p. 9-44.

PAIVA, Antônio Cristian Saraiva. Sujeito e laço social - a produção de subjetividade na arqueogenealogia de Michel Foucault. Rio de Janeiro: Relume Dumará, 2000, 229 p.

PORTOCARRERO, Vera. As ciências da vida: de Canguilhem a Foucault. Rio de Janeiro: Editora Fiocruz, 2009, 260 p.

SANTOS, Boaventura de Souza (Org.).Conhecimento prudente para uma vida decente: um discurso sobre as ciências revisitado. São Paulo: Cortez, 2003. 821 p.

VEIGA-NETO, Alfredo. Foucault e a Educação. Belo Horizonte: Autêntica, 2007. 159 p.

VEYNE, Paul. Foucault - seu pensamento, sua pessoa. Trad: Marcelo Jacques de Morais. Rio de Janeiro: Civilização Brasileira, 2011. 254 p.

ZAMBENEDETTI, Gustavo; SILVA, Rosane Azevedo Neves da. Cartografia e genealogia: aproximações possíveis para a pesquisa em psicologia social. Psicologia e Sociedade, Florianópolis, v. 23, n. 3, p. 454-463, 2011. 


\section{Agradecimento}

O trabalho aqui apresentado é composto por alguns resultados de pesquisa no nível de Mestrado em Psicologia financiada pela Fundação de Amparo à Pesquisa do Estado de São Paulo (FAPESP) - Processo 2012/14645-0.

Recebido em: $16 / 11 / 2014$

Revisão em: 26/11/2014

Aceite em: 12/12/2014

Ana Clara Magalhães Cunha é psicóloga. Mestre em Psicologia pela Universidade Estadual Paulista "Júlio de Mesquita Filho" - Faculdade de Ciências e Letras de Assis (Unesp/Assis). Bolsista da Fundação de Amparo à Pesquisa do Estado de São Paulo (FAPESP). Endereço para correspondência: Rua João Ramalho, 1238, casa 5. Vila Tênis Clube, CEP 19806-330, Assis/ SP. E-mail: anaclara.magalhaes@gmail.com

Cristina Amélia Luzio é professora Livre Docente em Saúde Mental e Saúde Coletiva e Professora do Programa de Pós-Graduação em Psicologia da Faculdade de Ciências e Letras de Assis - Universidade Estadual Paulista "Júlio de Mesquita Filho" - Faculdade de Ciências e Letras de Assis (Unesp/Assis).

E-mail: crisamelia@uol.com.br

Soraia Georgina Ferreira de Paiva Cruz é Professora Doutora no Departamento de Psicologia Evolutiva Social e Escolar da Universidade Estadual Paulista "Júlio de Mesquita Filho" - Faculdade de Ciências e Letras de Assis (Unesp/Assis).

E-mail: socruz@assis.unesp.br 